\title{
Green transportation analysis based on environmental logistics in China
}

\author{
LIU BING-JUN ${ }^{1 *}$ \\ North china electricity power university ,Beijing ,Beijing 100000,china \\ email515808928@qq.com
}

\begin{abstract}
Objective: emphasizing preventing the environment from being harmed by logistics, Then he analyses green transportation of the environmental logistics study. especially on the part of possible degree in china. Methods: Survey Analysis based on status of China. Results: Chinese people believe that at this stage the logistics of low prices for the realization of the higher cost of environment logistics, most people are willing to pay a higher cost, but China's current energy structure and the technical level is difficult to achieve in a short leap. Conclusion: Although green transport is extremely important in a ring of environmental logistics, it's the reality of today's China is difficult to significant improvement in the short term.
\end{abstract}

Keywords-environmental logistics; Green transportation; transportation improvement; marketing;

\section{DEFINITION OF ENVIRONMENT LOGISTICS}

Environmental logistics refers to the suppression of logistics, while damage to the environment in the logistics process, to achieve the purification of the logistics environment, so that logistics resources can be most fully utilized. It includes aspects of logistics operations and logistics management of the entire process of green. From the point of view of logistics operating procedures, including green transportation, green packaging, green distribution and processing. From the point of view of logistics management process, mainly from the environmental protection and resource conservation objective, to improve the logistics system, it is necessary to consider the positive aspects of environmental logistics, but also consider the reverse logistics system of supply chain green. Our environmental logistics mainly on recyclable express parcels, we mainly want to design and use can be repeatedly recycled use of green packaging, courier packaging to reduce losses, reduce costs and enhance the logistics enterprise's economic situation while recycling the packaging of the express delivery industry can greatly reduce the impact on the environment, environmental protection and resource conservation to reach goal.

\section{ELEMENTS OF GREEN TRANSPORTATION}

As the most important logistics activities, basic activities, transportation on the environment that causes severe pollution, noise pollution, in particular in transport itself, and air pollution, waste oil pollution, traffic jams and so on. The current problems of logistics and transport are: the unreasonable distribution logistics nodes, exacerbating the exhaust and noise pollution; large proportion of self-logistics enterprises, small proportion of third-party logistics, resulting in a plethora of social transport vehicles, causing load transport, convective transport, circuitous transportation anomaly. Data show that nearly 30 percent of global greenhouse gas emissions from the transportation sector, according to experts predict that China's logistics industry accounted for $7 \%$ to $8 \%$ of energy consumption. The key is to reduce green transport vehicles in the total mileage on the road.

Transport fuel consumption and exhaust emissions is one of the main logistics activities cause environmental pollution. Therefore, in order to build a environmental logistics, we must first make reasonable layout and planning of transport routes, by shortening the transportation routes, improve vehicle loading rate, scientific reduce cargo transport mileage and other measures to achieve energy reduction targets. Also, pay attention to the transport vehicle maintenance, use of cleaner fuels, reducing energy consumption and emissions contribute to achieve green transport. Green transportation improvements such way that rational planning major transport routes, the use of clean energy, improve loading rate and reduce cargo transport mileage.

For rational planning of transport routes, and now Shen Tong, Yun Da, SF and many other large logistics companies in china throughout the country to establish their own logistics network, combined with the current Internet technology for tracking parcels facts search customers can through a single number for the items where the logistics transit stations, managers and other information queries. At the same time the computer will generate optimized transport routes. In fact, this has basically reached the environmental logistics transportation from rational planning goals.

\section{Situation OF ChinA Logistics DeVElopMENT BASED ON LOGISTICS ELEMENTS}

For the use of clean energy, energy structure of China's transport and logistics market stabilized, from 2003 to 2012 the energy structure is still no essential change occurred at the same time with new energy-powered transport in research due to cost factors in each country, is still at a low level to promote a state. The development of modern logistics must prioritize environmental issues from the perspective of the environment needs to be 
improved logistics system, forming a symbiotic environment logistics management system. Currently, ISO14000 has become a large enterprise to enter the international market permits. ISO14000 two basic idea is to prevent pollution and continuous improvement, which requires enterprises to establish an environmental management system, to make the business activities, the impact of every aspect of the products and services on the environment is minimized. Environmental logistics will have a great ecological value, is the inevitable trend of the times, but also the future direction we should strive.

Actor in the national economy increasingly important role in the logistics industry, has become a major industry, becoming a sign of the times. Logistics including warehousing, transportation, freight forwarding, packaging, distribution, information processing and a series of links. The current development of China's logistics industry is being used by traditional logistics services to modern logistics passive active service. Modern logistics and traditional logistics compared to more systematic, intelligent. Not just a simple shift. Reflects a more value-added logistics services. Modern logistics logistics operations to achieve mechanization, automation, management, intelligent, kind and reasonable unobstructed circulation."Economic Daily" that the 2014 full-year total social logistics expects more than 210 trillion yuan, an increase of about $8 \%$; logistics industry more than 3.4 trillion yuan, an increase of about $9 \%$. Two indicators of growth have slowed slightly compared with the previous year, but still higher than GDP growth over the same period, growth in the range. Logistics costs will be more than 9.7 trillion yuan, an increase of about $8 \%$, the growth momentum continues to decline slightly. The ratio of total social logistics cost to GDP is about $17 \%$, the quality and efficiency of logistics development has improved. In 2008, the total social logistics reached 89.9 trillion yuan, an increase of 4.2 times compared to 2000 , an average annual increase of $23 \%$; the added value of the logistics industry 2 trillion yuan, an increase of 1.9 times compared to 2000, an average annual growth of $14 \%$. In 2008, the total value added logistics service industry accounted for $16.5 \%$, accounting for $6.6 \%$ of GDP.

Regional differences in the development of China's logistics great driving effect on economic growth also showed uneven patterns. From a regional point of view, the difference between the eastern faster, slower Midwest, the eastern coastal economically developed areas generally more developed than inland areas and the economic effect of the strong; from urban and rural location, suburban faster, farther from the center of the city than the countryside slow; resource characteristics from the point of view, the stock of large and high value resources are located in rural areas of the logistics industry developed rapidly, resource characteristics are not prominent and rely on traditional agriculture industry in the development of rural logistics slower. Rural logistics causes uneven development is multifaceted, but to solve these problems need to take reasonable development path and policies.

\section{A. Loading rate}

For improving the loading rate, loading rate of our existing courier saturated. China's express delivery business volume in 2013 to complete the 9.2 billion, ranking second in the world, an average of 6.8 delivery per person. For our sample survey in terms of our field visits to various courier company warehouse saturation above $70 \%$, if the peak of consumption, such as double-eleven Shopping Day, Chinese New Year eve, etc., it tends to "warehouse explosion" has become commonplace.but At present, the majority of our logistics business is changing from the traditional storage and transportation of goods and commercial enterprises, ministries and affiliated storage base ports, terminals and other transit agency locations over. As these companies grew out of a planned economy, is extensive management, fragmented product, its infrastructure capacity is far from meeting the needs of China's economic development. Performance in the transport capacity still can not meet the transportation needs, the main transportation corridor between supply and demand is still outstanding; warehouse storage facility behind most of the warehouse was built in the fifties and sixties of the 20th century, and is already quite old; modern container, spare parts transport development unhappy , our waterways containerized rate was $42 \%$, while the international community generally $60 \%$; less efficient special vehicles, cars to medium-sized petrol car-based, high energy consumption, low efficiency, low level of mechanization of loading and unloading.

\section{B. Freight transport}

For freight transport mileage in terms of reducing the actual logistics process is not easy to manage, transport and logistics process stream mileage in carbon emissions and energy consumption is positively correlated, which itself mainly by a reasonable degree of route planning and transportation from both near and far affect the control factors. Route planning for a reasonable degree of this factor, we analyze in this chapter on the first point to make an explanation, operators for the use of cost considerations and computer networks, we can say that in the current level of productivity, Express Logistics the route plan is reasonable and it is difficult to improve.

\section{GEOGRAPHICAL LOGISTICS ANALYSIS}

For the second factors, transport journey length refers shipping routes with distances between receipt. When we as a consignee of consumption, we assume his position is given constant, and our target is the whole market of consumer choice in the business, its position is non-stationary. And when we think manufacturers are shipped to the established position of consumers from across the country where the same is non-stationary. From theory to shorten the distance between them is either shipped to change or alter receipt. Before we discuss which way to change, we have to understand in this market who occupy the initiative does not change, that the parties to each other in order to provide more resources 
who passively. The essence of the problem in the end, he is a logistics supply market is a buyer's market or a seller's market. When not take hunger marketing sales in mainland China iphone6 just listed, mainland consumers eagerly chasing Hong Kong Shopping, pushed onto a iphone6 million. Just three months later, and now iphone6 sale now priced to compete with the influx and the dealer is only 4800yuan. So on single items, different periods in which the buyer and the seller's market is different. When this subject to a class of products or expansion of an industry, it tends to have very different inside. In view of this market, we believe we are going to discuss the delivery of goods throughout the supply of the market. Its subject is the online shopping website belongs to a series of b2b.c2c.o2o shopping platform. In such a market, information transparency, adequate supply of goods, the market is in a state of oversupply, consumer choice in the driving position, so in the current buyer's market, businesses and logistics companies can be reduced by increasing the delivery of supply points traffic and improve logistics efficiency. But in today's market, similar to the JD Mall and Su Ning Appliance has more storage base such shipments shopping platform is not much. And such 020 lucrative businesses and minority capital b2b businesses to pay taxes due and fixed bodies in the net price is still not on the market does not take advantage of shopping. $\mathrm{c} 2 \mathrm{c}$ b2b businesses and most businesses are still the main force in the online shopping market, with its resources can not support its build more storage, so now we envisaged community interaction and distribution of online shopping and the current stage is still difficult to achieve. In order to study the individual level of market, we do a brief survey. ( Sample size is 300)

TABLE I

\begin{tabular}{|c|c|c|}
\hline Point & YES & NO \\
\hline $\begin{array}{c}\text { Whether the consumer is willing } \\
\text { to pay more for environmental } \\
\text { logistics costs }\end{array}$ & $76 \%$ & $24 \%$ \\
\hline $\begin{array}{c}\text { Do you think China's logistics } \\
\text { costs excessive }\end{array}$ & $19 \%$ & $81 \%$ \\
\hline
\end{tabular}

\section{MARKET SELECTION THEORY}

We further analyze the factors for the second point, if we join the government in such a market conduct regulation of behavior to the behavior of both consumers and businesses. If the government's policy group is business correspondence, we will find businesses due to their different qualifications difficult to establish uniform standards and reasonable, and if the government is to encourage the type of behavior policy will be difficult to measure because of traffic and confusion, if the government's policy tend punitive enforcement behavior, it will be less qualified businesses will be forced out of the market has greatly disturbed the normal market order. For consumers, the situation is similar, for example, to encourage consumers to buy the product nearby, this policy will become empty useless, because consumers first consider the question of inexpensive commodity logistics and transportation-related degree is not high. This time we need to consider a third-party logistics companies, logistics companies if the state regulation, improve the actual cost of goods by improving to shipping. When consumers buy goods long distances to bear the freight will be more expensive to buy so nearby. But in practice, this assumption is difficult to set up in our survey $85 \%$ of consumers believe that the low postage prices. This is the case, China's cheap labor, cheap postage, mainland China except for a few remote areas, the differences are not large postage. Compulsory raise postage is greatly disturbed the market. Essentially to reduce traffic by depressing demand for economic development is very unfavorable

To promote the further development of the logistics industry, improve transport efficiency, reduce energy consumption, the US government attaches great importance to the joint operation of standardization and various transport modes of transportation equipment. 1991 promulgated the "intermodal Law", and vigorously promote the development of intermodal transport. "Strategic Plan for 2000-2005, the Department of Transportation," is one of the four proposed intermodal transportation system characteristics America. 1996, "US Department of Transportation Strategic Plan 1997-2002 fiscal year," pointed out, the US Transportation biggest challenge is to establish an international as the range in a variety of modes of transport in the form of combined transport, characterized by intelligently and natural environment contains including transport systems. 2025 "National Transportation Science and Technology Development Strategy" provides transportation or transportation of industrial structure and technological progress overall goal is: "Building a safe, efficient, adequate and reliable transport system, its scope is international, in the form of a comprehensive 
characterized by intelligence, nature is environmentally friendly. "Promulgation of these regulations and promotion strategy and planning at the national level, on the one hand to force logistics company focused on environmental issues, on the other hand indicates the direction of development of the logistics industry, and promote intermodal and other advanced management methods and technology in the logistics enterprises .

Transportation and logistics organizations in Europe ---- European freight forwarding organization also attaches great importance to the development of green logistics, transport, handling, management process to develop appropriate green standards, to strengthen guidance and planning role of government and business associations to green logistics, while encouraging enterprises to use the new concept of green logistics focus on the planning and construction of logistics facilities, it should be combined with the protection of the environment; restrictions against humanity and the most serious ecological development of road transport, and vigorously promote the railway electrification of transport to carry out the logistics activities, plus Large green logistics research and application of new technologies, such as transportation planning studies, and actively develop green packaging materials. They developed the following three objectives: To deal with the problem of global warming, emissions control measures to strengthen the organization in order to improve the efficiency of frequent among European logistics activities in order to achieve carbon dioxide "Kyoto Protocol" discharge reduction targets also adopted a series of coordinated policies and measures to vigorously promote the logistics body standard; promote transport efficiency and utilization of rail and domestic shipping, to conserve resources. For example, in 2010, to make long-distance transport groceries modular ratio reached all-European rail system and the European Commission put forward at the beginning of this century: not more than $50 \%$. To solve the air pollution problem. Watts to 20 years to strengthen the emissions, efforts to establish a unified European railway system, to achieve Osborn restrictions, development and popularization of low-pollution vehicles, the expansion of the role of whole continents ring road railway signal railway transport critical systems. The practice of recycling-oriented society, to build and promote the development of vein-type looking for logistics, transport, handling, management process flow system to develop, utilize rail and sea, to explore recycling society contribute to the corresponding green standards, strengthen the government and enterprises Association of green matter effective logistics system; WAN equipment waste reproduction facilities, etc.

\section{SUMMARY}

Although green transport is extremely important in a ring of environmental logistics, Taking into account the actual level of development of China's energy structure and the current level of technology, it's the reality of today's China is difficult to significant improvement in the short term.At same time, China's logistics industry is also being constantly developed and improved. While the logistics industry is quickly becoming an inevitable trend of the current restructuring and development of the logistics industry from the traditional to the modern logistics logistics. Under continuous development of digital information, the atmosphere of the national policy support, the logistics industry will increasingly become an important part of the national economy.

\section{REFERENCES}

[1] Zheng Guihua. Our packaging levy pollution tax sense and vision. Finance Theory and Practice, 1999

[2] Chen Siyuan, Dong Min, Wang Jingan so on. Supply chain management research and thinking on the carbon footprint., 2011

[3] Wang Wei, Lin Jian Yi, Cui Shenghui so on. Research Summary carbon footprint analysis, Environmental Science and Technology, 2010

[4] Li Gang, the development trend of China's express delivery industry analysis, logistics engineering and management,2010

[5] H -J,Dunn Environmentally Responsible Logistics Systems, 1995

[6] Wang Changqiong, Background and Development Strategies of Environmental logistics , Logistics Technology ,2002

[7] Li hongYue, domestic situation and development of Environmental logistics, Economic Issues, 2007

[8]Sun Xiumei, Xin Guang Qian, bottlenecks in the development of environmental logistics and Countermeasures,Chinese Circulation Economy,2007

[9] Jiang Xiaoyan, environmental logistics, Chinese Foreign ,2011

[10] Wang Changqiong connotation of environmental logistics, characteristics and strategic value, Chinese Circulation Economy , 2004 